\title{
MEDIASI DAYA TARIK FASHION DALAM HUBUNGAN KEINOVASIAN PRODUK DENGAN KINERJA PEMASARAN
}

\author{
Hendar \\ Fakultas Ekonomi, Universitas Islam Sultan Agung, Semarang \\ hendar@unissula.ac.id
}

\begin{abstract}
This paper aims to investigate and examine the role of fashion attractiveness in mediating the relationship between product innovation (uniqueness and novelty) and marketing performance. A total of 229 small businesses in Indonesia were selected to be tested for regressional relationships of the four constructs. This study finds a positive influence of product novelty and uniqueness on fashion attractiveness, yet it does not affect marketing performance. Mediation analysis shows that fashion attractiveness plays an important role in bridging the relationship of product novelty and product uniqueness on marketing performance. Through an in-depth examination of a variety of literature about dynamic capabilities, entrepreneurial marketing, and company performance, this paper offers a unique analysis of the correlation of product novelty and product uniqueness on fashion attractiveness as well as its impact on marketing performance in the small-scale fashion industry. Conceptual discussion and empirical result of the study extend previous researches on the culture of product innovation in small businesses.
\end{abstract}

Keywords: Keinovasian Produk, Kebaruan Produk, Keunikan Produk, Day Tarik Fashion, Kinerja Pemasaran

\section{PENDAHULUAN}

Keinovasian produk merupakan salah satu kunci sukses perusahaan dalam pengembangan produk baru (Cooper dan Kleinschmidt, 2007). Faktor inilah yang mendorong para peneliti tertarik untuk mengkaji secara detail efek keinovasian produk pada kinerja perusahaan, termasuk kinerja pemasaran didalamnya (Avlonitis dan Salavou, 2007; Salavou dan Avlonitis, 2008; McNally, dkk., 2010). Beberapa kajian empirik telah membuktikan bahwa keinovasian produk memberikan efek signifikan terhadap kinerja pemasaran (Lee, 2008; Matzler, $d k k$., 2008), namun beberapa peneliti lain menemukan sesuatu yang bertentangan (Yalcinkaya, dkk., 2007; Acar dan Acar, 2012). Karena itu ada pertanyaan serius tentang bagaimana kontribusi yang sebenarnya keinovasian produk terhadap kinerja pemasaran.

Menurut McNally dkk. (2010), perbedaan hasil penelitian tersebut umumnya dengan kontingensi berbagai pengukuran dan faktor kontekstual. Keinovasian produk sering dijelaskan sebagai kebaruan produk (Garcia dan Calantone, 2002) dan secara operasional diukur dengan kebaruan bagi perusahaan dan kebaruan bagi pasar (Avlonitis dan Salavou, 2007). Keinovasian produk juga bisa dijelaskan sebagai keunikan produk yang diukur dengan perbedaan fitur, kemanfaatan, kualitas dan keunggulan teknologi (Avlonitis dan Salavou, 2007). Di sisi lain, faktor-faktor kontekstual seperti jenis produk (barang atau jasa) dan jenis industri (industri makanan, elektronik, otomotif, dan lain-lain) juga menjadi faktor 
kunci yang memungkinkan perbedaan hasil penelitian di atas. Penelitian ini fokus pada kajian keinovasian produk busana muslim yang secara rinci dijelaskan melalui dua dimensi yang terpisah, yaitu kebaruan produk dan keunikan produk. Dengan fokus pada industri busana muslim skala mikro, kecil dan menengah, penelitian ini berusaha menjawab apakah perusahaan dengan kebaruan dan keunikan produk fashion dapat memberi pengaruh positip pada kinerja pemasaran.

Pada penelitian ini keinovasian produk bukan satu-satunya faktor yang dipertimbangkan sebagai penentu kinerja pemasaran usaha mikro, kecil, dan menengah; anteseden lain daya tarik fashion ditetapkan sebagai pendorong yang dominan. Beberapa penelitian telah menunjukkan daya tarik produk memiliki hubungan positip dengan kinerja pemasaran (Ferdinand dan Fitriani, 2015). Penelitian lain juga menunjukkan keinovasian produk menjadi driver penting dari daya tarik produk (Carbon dan Leder, 2005). Itu berarti daya tarik produk menjadi mediasi dalam hubungan atara keinovasian produk dengan kinerja perusahaan. Dalam konteks pasar fashion, itu berarti daya tarik fashion berpotensi sebagai mediasi dalam hubungan antara keinovasian produk dengan kinerja pemasaran.

Kinerja pemasaran secara khusus dipandang secara luas sebagai kepentingan mendasar bagi manajer pemasaran (Kotler dan Keller, 2009), paling tidak karena manajer pemasaran menilai perusahaan berdasarkan arus kas masa depan yang diharapkan investor (Srivastava, dkk., 1999). Oleh karena itu, manajer pemasaran perlu terus berinovasi dalam hal produk untuk menghasilkan produk yang menarik bagi pelanggan, hingga pada akhirnya kinerja pemasaran superior dapat diperoleh. Sayangnya, penelitian yang mengkaitkan keinovasian produk dengan kinerja pemasaran yang dimediasi daya tarik fashion masih jarang dilakukan. Masih sangat terbatas pengetahuan tentang hubungan antara keinovasian produk, daya tarik fashion dan kinerja pemasaran. Penelitian ini membahas kesenjangan pengetahuan ini dengan memeriksa bagaimana keinovasian produk yang spesifik dapat mempengaruhi kinerja pemasaran pada usaha kecil dan menengah.

Penelitian ini menggunakan analisis model structural untuk mengidentifikasi asosiasi keseluruhan antara variabel dependen tunggal kinerja pemasaran; dua variabel independen kebaruan dan keunikan produk; dan satu variabel mediasi daya tarik fashion. Hubungan variabel independen dengan dependen yang dimediasi daya tarik fashion dimodelkan di sini untuk mengatasi kesenjangan di atas. Pengujian mediasi dalam model ini penting untuk menjelaskan bagaimana hubungan antara dimensi keinovasian produk dengan kinerja pemasaran. Paper ini dirancang sebagai berikut, pertama, konstruk keinovasian produk dijelaskan kedalam dua dimensi, yakni kebaruan produk dan keunikan produk. Kedua, hipotesis ditetapkan untuk menjelaskan bagaimana hubungan dua dimensi keinovasian produk dengan daya tarik fashion dan kinerja pemasaran. Ketiga, metode penelitian dijelaskan, dan hasil analisis diuraikan. Keempat, menyimpulkan dengan diskusi tentang pentingnya hasil penelitian untuk para peneliti maupun praktisi.

Studi ini membuat dua kontribusi untuk kemajuan pengetahuan dalam domain penting ini. Pertama, membangun teori pertumbuhan endogen dari ekonomi serta teori berbasis sumber daya (RBV) dan kapabilitas dinamis (DC) dari manajemen strategis dengan mengembangkan kerangka teoritis yang menghubungkan keinovasian produk, product attractiveness, dengan kinerja pemasaran usahan kecil dan menengah. Kedua, memberikan wawasan baru yang alamiah dan driver keinovasian pada kinerja pemasaran. 


\section{Daya Tarik Fashion (DTF)}

Literatur manajemen pemasaran menjelaskan bahwa untuk mencapai kinerja produk yang lebih baik, setiap pemasar perlu merancang segmen pasar; menetapkan target pasar; dan menciptakan, mengkomunikasikan serta menyampaikan proposisi nilai kepada pelanggan dengan atribut-atribut produk yang menarik (Kotler dan Keller, 2009; Lamb, dkk., 2010). Atribut produk adalah segala sesuatu yang melekat dalam sebuah produk yang menjelaskan manfaat yang ditawarkan produk kepada pelanggan, seperti fitur, kualitas, desain dan gaya (Kotler dan Keller, 2009). Sebuah produk fashion memiliki atribut kenyamanan, kesederhanaan, estetika, keamanan, keserasian, kebanggaan, kesantunan, dan karakteristik lain yang bermanfaat bagi konsumen. Atribut-atribut itulah yang memuaskan konsumen, bukan pada seberapa banyak produk fashion yang digunakan. Jadi produk hanyalah alat yang digunakan untuk menyampaikan atribut dalam suatu proses konsumsi (Lancaster, 1966).

Ada 3 (tiga) jenis atribut produk yang dapat ditawarkan kepada pelanggan, yakni atribut kinerja, penampilan dan komunikasi (Lee, dkk., 2011). Atribut kinerja berkaitan dengan sejauhmana sebuah produk mampu memenuhi fungsinya sesuai yang diharapkan, termasuk kemudahan penggunaan, kegunaan produk, dan inovasi teknologi yang dikandung sebuah produk (Wood, 2007). Atribut penampilan berhubungan dengan jumlah daya tarik visual yang dapat ditampilkan sebuah produk. Daya tarik visual biasanya berhubungan dengan persepsi seseorang tentang nilai estetika sebuah produk terkait faktor desain seperti warna, proporsi, bentuk, dan materi. Sedangkan atribut komunikasi berkaitan dengan kemampuan suatu produk dalam membantu pengguna mengekspresikan diri atau menampilkan identitas dan nilai-nilai untuk diri sendiri maupun untuk orang lain (Lee $d k k$., 2011).
Atribut produk merupakan sumber daya tarik produk. Menurut Chan, dkk. (2010), daya tarik produk merupakan kemampuan suatu produk untuk memenuhi preferensi pribadi pada set atribut yang telah ditetapkan. Daya tarik produk juga dipandang sebagai efek visual yang diperoleh dari karakteristik desain dan nilai estetika sebuah produk yang merangsang atau membangkitkan evaluasi kognisi pelanggan (Chen, 2010). Mengingat fashion adalah istilah luas yang meliputi produk atau pasar di mana terdapat unsur gaya yang cenderung berumur pendek (Christopher, dkk., 2004; Barnes, dkk., 2006), maka daya tarik fashion merupakan sekumpulan atribut fashion yang ditawarkan kepada konsumen atau pelanggan sebagai basis mereka dalam memenuhi preferensinya. Menurut Fuentes dan Quiroga (2009), fashion adalah sebuah fenomena sosial yang luas dan tidak dapat dihindari dari kehidupan modern. Pada tataran mendasar, fashion berfungsi sebagai penutup tubuh, perlindungan, kesopanan, dan daya tarik. Namun pada tataran yang lebih tinggi, fashion telah tumbuh menjadi bagian dari gaya hidup seseorang. Melalui fashion terkini seorang pemakainya bisa menunjukkan status dan kualitas gaya hidupnya. Saat ini, tren fashion telah menyusup ke dalam ideologi konsumen yang merubah cara pandang fashion sebagai gaya hidup dengan merek sebagai medianya. Fashion merupakan fenomena kultural yang dipahami sebagai satu sistem penandaan, identitas bagi keyakinan, nilai-nilai, ide-ide dan pengalaman yang dikomunikasikan melalui praktek-praktek, artefak-artefak, dan institusi-institusi (Fuentes dan Quiroga, 2009). Oleh karena itu, atribut fashion yang menjadi daya tarik konsumen berkaitan dengan aspek fungsional (seperti kehangatan, kenyamanan, kemudahan perawatan, kelembutan bahan, daya tahan, ketebalan bahan, dan kadar serat); aspek penampilan (gaya, keselarasan, warna dan cara pengerjaan); aspek simbolis (trendiness dan merek); dan atribut harga (Zhang, dkk., 
2002). Mengingat fashion muslim adalah pakaian berbasis religi, maka kreasi daya tarik fashion tidak hanya dibangun berbasis pada perkembangan mode, tetapi juga perlu menyertakan norma-norma religi. Ini melibatkan beberapa kriteria, seperti : (1) desain sesuai dengan tuntunan syariah, (2) memenuhi unsur kesederhanaan dan kesantunan, (3) desain produk yang estetik, (4) model dan gaya mengikuti perkembangan mode, dan (5) bahan yang yang digunakan memenuhi standar kualitas tertentu.

\section{Keinovasian Produk}

Literatur entrepreneurship menjelaskan keinovasian sebagai bagian dari orientasi entrepreneurial yang menjelaskan kecenderungan perusahaan untuk terlibat dan mendukung ide-ide baru, kebaruan, eksperimen, dan proses kreatif yang dapat menghasilkan produk, layanan, atau proses teknologi baru (Lumpkin dan Dess, 1996). Keinovasian produk dengan demikian merupakan kecenderungan perusahaan untuk terlibat dan mendukung ide-ide baru untuk menghasilkan produk baru, baik baru untuk perusahaan maupun baru untuk industri atau pasar (Garcia dan Calantone, 2002). Kebaruan produk untuk perusahaan berarti produk yang dihasilkan benarbenar untuk pertama kalinya diproduksi perusahaan, meskipun di pasar mungkin sudah tersedia produk yang serupa yang dihasilkan perusahaan lain. Kebaruan produk untuk pasar terjadi jika benar-benar pertama sebuah produk diperkenalkan di pasar dan belum pernah ada yang menawarkan produk serupa di pasar (Sandvik dan Sandvik, 2003; Clausen, dkk., 2013).

Konsep keinovasian produk juga dapat dijelaskan melalui tiga dimensi, yakni kebaruan produk untuk pelanggan, kebaruan produk untuk perusahaan, dan keunikan produk (Avlonitis dan Salavou, 2007). Dari sudut persepsi pelanggan, sebuah produk dikatakan baru untuk pelanggan jika masih banyak pelanggan yang sedang belajar memahami produk yang ditawarkan. Mereka mungkin membutuhkan waktu yang cukup untuk memahami produk baru yang ditawarkan dan masih mengalami kesulitan dalam memahami konsep produk. Mereka juga mungkin belum mengetahui suatu produk baru atau sedang mencobanya di pasar. Sedangkan sebuah produk dikatakan memiliki keunikan jika menawarkan lebih banyak kemungkinan penggunaan bagi pelanggan, memiliki fitur unik bagi pelanggan, memenuhi kebutuhan yang lebih banyak bagi pelanggan, berkualitas tinggi dan memiliki unggul dalam teknologi (Avlonitis dan Salavou, 2007).

Keinovasian produk dalam penelitian ini dikembangkan menjadi dua dimensi, yakni kebaruan produk bagi pasar dan keunikan produk baru. Tiga alasan mendasar pemilihan ini, pertama, keyakinan bahwa kesuksesan produk baru sangat tergantung pada penerimaan pasar. Kedua, kerangka acuan untuk menilai kebaruan dan keunikan produk untuk perusahaan tergantung pada perubahan faktor-faktor spesifik milik perusahaan ketika pengembangan produk baru, seperti teknologi dan sumber daya pemasaran (Garcia dan Calantone, 2002), sehingga inovasi baru bagi suatu perusahaan mungkin tidak baru bagi pasar. Ketiga, banyak peneliti yang menjelaskan faktor-faktor penentu inovasi produk dari sudut pandang pasar atau pelanggan (Moorman, 1995).

\section{Keinovasian Produk dan Daya Tarik Fashion}

Literatur pemasaran menjelaskan, untuk menghasilkan daya tarik produk yang lebih baik, setiap perusahaan perlu terus menerus melakukan perubahan dalam atribut produk. Ini mengisyaratkan perlunya keinovasian produk dalam perusahaan untuk terus memperbaiki bentuk, fitur, adaptabilitas, kualitas kinerja, kualitas kesesuaian, ketahanan, kehandalan, kemudahan perbaikan, gaya dan desain (Kotler dan Keller, 2009). Setiap produk 
menawarkan daya tarik atribut yang berbeda bagi konsumen dan masingmasing konsumen memiliki preferensi yang berbeda-beda terhadap atrbut tersebut. Daya tarik yang dimaksud termasuk daya tarik karena pengakuan sebelumnya, daya taik fungsional, daya tarik simbolik, dan daya tarik intrinsik (Mason dan Bequette, 1998; Lievens dan Highhouse, 2003; Hersleth, $d k k ., 2015)$. Daya tarik karena pengakuan sebelumnya muncul ketika pengalaman konsumen sebelumnya telah membangkitkan daya sensorik seorang individu untuk lebih akrab dengan sebuah produk. Daya tarik karena fungsional produk muncul ketika citra yang dihasilkan dari interpretasi atau persepsi individu terhadap fitur produk adalah sangat relevan. Daya tarik karena simbolis biasanya muncul ketika konsumen merasakan adanya nilai-nilai pribadi dan sosial atas produk yang dikonsumsinya (Chang, dkk., 2007). Sedangkan daya tarik intrinsic biasanya muncul ketika konsumen melihat secara visual keindahan yang melekat pada bentuk produk. Ada kecenderungan setiap orang untuk memilih produk yang lebih menarik secara visual dibandingkan dengan produk alternatif yang secara fungsional setara (Fandos dan Flavia'n, 2006). Oleh karena itu, perusahaan yang memiliki kecenderungan untuk menghasilkan kebaruan dan keunikan produk (yang tercermin dari kapasitasnya dalam mengembangkan atribut produk) akan memiliki potensi yang lebih baik dalam menghasilkan produk dengan daya tarik yang lebih baik. Pada akhirnya perusahaan yang mampu menciptakan daya tarik produk yang lebih baik akan lebih mungkin untuk membuat pembeli tertarik menyelidiki produk tersebut lebih lanjut (Knotts, $d k k$., 2012).

Pengukuran daya tarik dan keinovasian adalah tantangan utama dalam bidang kognisi terapan. Keinovasian didefinisikan merupakan orisinalitas berdasarkan pengenalan ide-ide baru. Keberhasilan penerapan produk baru tergantung pada keinovasian desain dan daya tarik yang mereka rasakan (Carbon dan Leder, 2005). Desain yang sangat inovatif meningkatkan daya tarik, sedangkan keinovasian desain rendah dianggap kurang menarik karena sifatnya yang menuntut rendah. Dengan demikian, hanya desain inovatif yang menunjukkan peningkatan daya tarik (Carbon dan Leder, 2005). Itu berarti keunikan dan kebaruan produk memberi efek positip terhadap daya tarik produk. Dalam pandangan Knotts dkk. (2012), penampilan produk perlu terus ditingkatkan untuk memenuhi selera konsumen yang terus berubah. Perusahaan perlu terus menghasilkan dan memperkenalkan produk baru dengan daya tarik yang lebih kuat bagi konsumen. Pada industri fashion muslim, daya tarik fashion sangat mungkin diperoleh dari hasil kreativitas perusahaan dalam menghasilkan kebaruan atau keunikan produk yang memadukan atribut-atribut fashion dengan atribut religiusitas. Oleh karena itu patut diduga bahwa perusahaanperusahaan yang fokus pada kebaruan dan keunikan produk akan memiliki potensi menghasilkan daya tarik fashion yang lebih baik.

$\mathrm{H} 1$ : Perusahaan dengan kebaruan produk yang lebih baik akan lebih mampu dalam meningkatkan daya tarik fashion

$\mathrm{H} 2$ : Perusahaan dengan keunikan produk yang lebih baik akan lebih mampu dalam meningkatkan daya tarik fashion

\section{Keinovasian Produk dan Kinerja \\ Pemasaran}

Kinerja pemasaran merupakan proses multidimensi dan dapat dijelaskan melalui efektivitas, efisiensi, dan adaptabilitas aktivitas pemasaran (Morgan, dkk., 2002; Gao, 2010). Dari sudut pandang pemasaran, empat ukuran kinerja pemasaran mendapat perhatian dari beberapa peneliti, yakni kepuasan pelanggan (Oliver, 1997), kualitas pelayanan (Parasuraman, $d k k$., 
1985), ekuitas merek (Aaker, 1996), dan loyalitas pelanggan (Zineldin, 2006). Sementara itu, beberapa peneliti lain menjelaskan kinerja pemasaran sebagai prestasi perusahaan dalam mencapai tujuan pertumbuhan penjualan, peningkatan pangsa pasar, peningkatan pelanggan baru, mempertahankan pelanggan yang sudah ada, meningkatkan rasio laba bersih terhadap penjualan dan meningkatkan kepuasan pelanggan (Merrilees, dkk., 2011; Prasertsang dan Ussahawanitchakit, 2011; Soliman, 2011; Hendar, dkk., 2017).

Banyak penelitian empirik yang membuktikan bahwa keinovasian produk (kebaruan dan keunikan produk) menjadi driver yang kuat untuk kinerja pemasaran (Lee, 2008; Alpay, dkk., 2012; Atalaya, dkk., 2013). Menurut Millson (2013), adanya relasi antara keinovasian produk dengan kesuksesan produk baru, menunjukkan bahwa kecenderungan perusahaan untuk menghasilkan produk baru yang berkualitas dan memiliki keunikan yang khas akan mampu meningkatkan kinerja pasar produk baru. Peneliti lain menjelaskan keunikan produk baru menjadi pendorong kinerja produk, sehingga bagi perusahaan keunikan produk harus dijadikan budaya organisasi, nilai dan keyakinan untuk melaksanakan inovasi produk dengan sukses (Avlonitis dan Salavou, 2007). Dengan cara seperti itu, keunikan produk tidak hanya berperan besar dalam meraih keunggulan posisional produk, tetapi juga berperan dalam meningkatkan kesuksesan produk baru. Di sisi lain, Ortega dan Garcia-Villaverde (2011) menjelaskan bahwa kebaruan produk sebagai pioneer orientation bagi produk baru dalam memasuki pasar benarbenar menjadi penggerak utama kinerja pemasaran.

Beberapa temuan tersebut menunjukkan bahwa keinovasian produk, baik dalam dimensi kebaruan produk maupun keunikan produk, memiliki hubugan positip dengan kinerja perusahaan, termasuk kinerja pemasaran di dalamnya. Oleh karena itu patut diduga bahwa dalam industri busana muslim, kebaruan produk dan keunikan produk berpengaruh positip terhadap kinerja pemasaran.

H3 : Perusahaan dengan kebaruan produk yang lebih baik akan lebih mampu dalam meningkatkan kinerja pemasaran

H4 : Perusahaan dengan keunikan produk yang lebih baik akan lebih mampu dalam meningkatkan kinerja pemasaran

\section{Daya Tarik Fashion dan Kinerja Pemasaran}

Dalam perspektif pelanggan, daya tarik yang dirasakan sangat mempengaruhi respon pelanggan pada sebuah desain produk (Giese, dkk., 2014), sehingga daya tarik produk mempengaruhi perilaku pembelian pelanggan. Teori dan bukti empiris secara konsisten menunjukkan bahwa daya tarik memainkan peran penting dalam kemampuan persuasif rangsangan pemasaran dan minat beli. Daya tarik menentukan sejauh mana suatu produk mampu memikatkonsumen untuk melakukan pembelian produk tersebut. Produk-produk yang memiliki daya tarik yang kuat baik yang timbul karena fungsinya, pengalaman mengkonsumsi, simbolik maupun nilai intrinsic yang melekat pada produk baru akan menjadi rangsangan konsumen untuk melakukan pembelian produk baru. Dari sudut pandang perusahaan, hal tersebut berarti kemampuan perusahaan untuk menawarkan daya tarik produk baru (termasuk busana muslim) akan menentukan kinerja pemasaran. Dengan menghubungkan daya tarik produk dan tanggapan pelanggan sepanjang sejarah kampanye pemasaran, perusahaan dapat mengevaluasi strategi bisnis dilihat dari perspektif pemasaran dan pengembangan produk untuk menciptakan nilai pelanggan dan menghasilkan keuntungan yang maksimal (Chan dkk., 2010). Itu berarti kinerja pemasaran sangat tergantung 
pada sejauh mana perusahaan mampu menciptakan dan menawarkan atribut yang menarik bagi pelanggannya. Pada pasar fashion muslim, perusahaan-perusahaan yang mampu menghasilkan daya tarik produk yang berbasis pada perkembangan fashion dan norma-norma religi atau yang menunjang komitmen keagamaan tertentu akan memiliki potensi yang kuat meningkatkan kinerja pemasarannya.

H5 : Perusahaan dengan daya tarik fashion yang lebih baik akan lebih mampu dalam meningkatkan kinerja pemasaran

\section{Peran Mediasi Daya Tarik Fashion}

Carbon dan Leder (2005) telah menunjukan keinovasian desain sebagai basis dalam meningkatkan daya tarik produk. Itu berarti keunikan dan kebaruan produk memberi efek positip terhadap daya tarik produk. Sementara itu, dalam penelitian berbasis iconik produk, Ferdinand dan Fitriani (2015) menunjukkan bahwa daya tarik produk ikonik akulturatif memegang peran strategis dalam meningkatkan kinerja pemasaran. Dengan logika berpikir seperti itu, daya tarik produk memiliki potensi untuk menjadi mediasi dalam hubungan antara keinovasian produk dengan kinerja pemasaran.

Pada pasar fashion muslim, perusahaanperusahaan yang mampu menghasilkan daya tarik produk yang berbasis pada perkembangan fashion dan norma-norma religi (syariah) akan memiliki potensi yang kuat meningkatkan kinerja pemasarannya. Penelitian ini mengajukan daya tarik fashion sebagai variabel yang memediasi hubungan keinovasian produk dengan kinerja pemasaran. Variabel tersebut dipilih dengan dasar pemikiran bahwa pada segmen pasar berbasis religi, perusahaan dengan kebaruan dan keunikan produk fashion yang mampu menghasilkan produk dengan daya tarik fashion yang lebih baik adalah yang mampu menghasilkan kinerja pemasaran yang lebih tinggi. Oleh karena itu, hipotesis 6 dan 7 adalah :

H6. Daya tarik fashion memediasi hubungan kebaruan produk dengan kinerja pemasaran.

H7. Daya tarik fashion memediasi hubungan keunikan produk dengan kinerja pemasaran.

\section{Metode \\ Desain Survey}

Penelitian ini menggunakan desain survei deskriptif untuk mengevaluasi proposisi yang tercantum di atas. Pemilik, pengelola atau pemilik yang sekaligus pengelola UMKM busana muslim di Jawa Tengah ditetapkan sebagai populasi dalam penelitian ini. Anggota sampel yang dipilih adalah mereka yang sudah berpengalaman lebih dari 3 tahun di bisnis yang sama, pendidikan minimal SMU, dan memiliki omzet penjualan tahunan maksimal 2,5 milyar rupiah. Para responden dipilih berdasarkan metode snowball sampling. Data diperoleh dari pendistribusien kuesioner kepada 427 responden yang berada di 11 Kabupaten I Kota di Jawa Tengah. Kuesioner disampaikan petugas secara langsung kepada responden yang dipilih. Sebelumnya petugas survey telah dilatih terlebih dahulu agar pengumpulan data dapat secara efektif dan efisien. Dari total kuesioner yang diberikan kepada responden, 406 kuesioner yang dikembalikan (95.08\%). Evaluasi akhir terhadap kuesioner yang terkumpul ternyata 77 kuesioner dinyatakan rusak dan outlier (18.97\%), sehingga tinggal 329 kuesioner $(81.03 \%)$ yang masuk akal untuk survei ini. Responden yang terpilih terdiri dari $77.51 \%$ wanita dan $22.49 \%$ pria yang besar berusia antara 25 tahun hingga 50 tahun. Mereka sebagian besar adalah pemilik dan sekaligus pengelola UMKM busana muslim yang telah berkeluarga dan telah bekerja lebih dari 3 tahun. Sebagian besar $(65.35$ \%) berpendidikan SLTA, 9.73 \% Diploma dan $24,92 \%$ Sarjana. 


\section{Instrumen}

Kajian literatur yang dilakukan telah menghasilkan serangkaian item yang terkait dengan kebaruan produk, keunikan produk, daya tarik fashion dan kinerja pemasaran. Untuk menjelaskan kebaruan dan keunikan produk, item dihasilkan dengan mengadaptasi pandangan Avlonitis dan Salavou (2007). Kebaruan produk merupakan kecenderungan perusahaan untuk menghasilkan produk baru dengan desain, model, corak maupun jenis bahan yang yang berbeda dengan produk lama. Sedangkan keunikan produk didefinisikan sebagai kecenderungan perusahaan untuk menghasilkan produk baru yang berbeda dengan produk yang dihasilkan pesaing, baik dalam desain, model, corak maupun jenis bahan yang digunakan. Daya tarik fashion merupakan efek visual desain dan estetika suatu produk fashion yang dibuat berdasarkan aturan-aturan religi sebagai atribut yang ditawarkan untuk memenuhi preferensi pribadi konsumen. Untuk mengukur kinerja pemasaran, item dihasilkan dengan mengadaptasi pandangan Merrilees dkk. (2011), Healy, dkk. (2014) dan Hendar dkk. (2017). Kinerja pemasaran didefinisikan secara operasional sebagai prestasi perusahaan dalam mencapai tujuan pertumbuhan hasil penjualan, peningkatan volume penjualan, dan peningkatan jumlah pelanggan. Tiga instrument digunakan untuk mengukur kebaruan produk, empat untuk keunikan produk, enam untuk daya tarik fashion, dan tiga untuk kinerja pemasaran (Tabel 1). Skala interval 1 sampai 10 digunakan untuk mengukur masing-masing instrument. Skor 1 menunjukkan sangat tidak setuju atas sebuah pernyataan yang diajukan dan skor 10 menunjukkan sangat setuju.

\section{Teknik Analisis Data}

Untuk memvalidasi skala dan menguji hubungan yang dihipotesiskan, pemodelan persamaan struktural menggunakan AMOS 22.00 digunakan. Confirmatory Factor
Analysis Model digunakan untuk menguji multidimensionalitas dari suatu konstruk teoritis (uji validitas konstruk). Selain itu, SEM juga digunakan sebagai alat uji komprehensif untuk full model structural. Analisis data mengikuti proses yang dianjurkan oleh Hair, dkk. (2010). Pertama, membuat model diagram jalur hubungan kausalitas antar konstruk beserta indikatornya. Kedua, menguji unidimensionalitas masing-masing konstruk dengan konfirmatory factor analisis. Ketiga, melakukan estimasi persamaan full model structural untuk indicator yang telah lolos uji konfirmatori. Keempat, membahas konvergensi dan validitas diskriminan sebelum pindah ke analisis substantif. Kemudian, meskipun pendekatan statistik utama untuk menguji mediasi adalah pemodelan regresi hierarkis (Baron dan Kenny, 1986), penelitian ini mengikuti logika dan rekomendasi dari sarjana lain (Sobel, 1982; Preacher dan Hayes, 2008; Hayes dan Preacher, 2014) dan menggunakan pemodelan persamaan struktural untuk menguji mediasi, seperti prediksi $\mathrm{H} 6$ dan $\mathrm{H} 7$.

\section{Hasil Analisis Data}

Hasil analisis faktor konfirmatori (CFA) untuk sampel lengkap dilaporkan dalam penelitian ini. Ada 16 indikator yang diamati masing-masing 3 indikator kebaruan produk, 4 indikator keunikan produk, 6 indikator daya tarik fashion dan 3 indikator kinerja pemasaran untuk mendapatkan 16 nilai louding factor $(\lambda 1-\lambda 16)$ yang relevan. Penilaian unidimensional dilakukan dengan memeriksa perkiraan general least square standardized estimates factor louding yang berada di atas 0,6 (Hair dkk., 2010). Hasil analisis CFA, louding factor untuk semua variabel laten yang diamati memiliki validitas yang baik karena memiliki nilai di atas 0,6 (Tabel 1). Ini berarti semua indikator dapat digunakan untuk menjelaskan konstruk laten yang diamati.

Menurut Hair dkk. (2010), reliabilitas konstruk yang tinggi menunjukkan konsistensi internal, artinya indikator secara 
Tabel 1.

Hasil analisis faktor konfirmatori untuk pengukuran model

\begin{tabular}{|c|c|c|}
\hline Kebaruan produk (KebP) & $\lambda$ & p-value \\
\hline Perbaikan terus desain produk (busana muslim) yang ditawarkan & 0.665 & 0.000 \\
\hline Rutinitas memperkenalkan produk (busana muslim) dengan model baru ke pasar & 0.684 & 0.000 \\
\hline $\begin{array}{l}\text { Kontinyuitas dalam penyesuaian kualitas bahan baku produk dengan kebutuhan } \\
\text { pelanggan }\end{array}$ & 0.690 & 0.000 \\
\hline \multicolumn{3}{|l|}{ Keunikan Produk (KeuP) } \\
\hline $\begin{array}{l}\text { Keunikan desain produk (busana muslim) perusahaan atas desain produk } \\
\text { pesaing }\end{array}$ & 0.762 & 0.000 \\
\hline Keunikan model produk (busana muslim) perusahaan atas model produk pesaing & 0.717 & 0.000 \\
\hline Keunikan corak produk (busana muslim) perusahaan atas corak produk pesaing & 0.664 & 0.000 \\
\hline $\begin{array}{l}\text { Keunikan bahan baku produk (busana muslim) perusahaan atas bahan baku } \\
\text { produk pesaing }\end{array}$ & 0.724 & 0.000 \\
\hline \multicolumn{3}{|l|}{ Daya Tarik Fashion (DTF) } \\
\hline Desain & 0.726 & 0.000 \\
\hline Keindahan (estetika) & 0.625 & 0.000 \\
\hline Style (gaya) & 0.676 & 0.000 \\
\hline Kesederhanaan & 0.756 & 0.000 \\
\hline Kesantunan & 0.698 & 0.000 \\
\hline Kenyamanan & 0.779 & 0.000 \\
\hline \multicolumn{3}{|l|}{ Kinerja Pemasaran (KP) } \\
\hline Pertumbuhan hasil penjualan perusahaan selama kurun waktu 3 tahun terakhir & 0.762 & 0.000 \\
\hline Peningkatan volume penjualan perusahaan selama kurun waktu 3 tahun terakhir & 0.753 & 0.000 \\
\hline Peningkatan jumlah pelanggan perusahaan selama kurun waktu 3 tahun terakhir & 0.717 & 0.000 \\
\hline $\begin{aligned}{ }^{a} X^{2} & =118.066 ; \text { DF }=98, \text { Probability } 0.082, \text { GFI }=0.955, \text { AGFI }=0.938, \text { TLI }=0.921 \\
& =0.025, \text { CMIM/DF }=1.205, \text { Hoetler01 }=371\end{aligned}$ & $\mathrm{I}=0.9$ & RMSEA \\
\hline
\end{tabular}

Sumber : Data primer yang diolah, 2017

konsisten mewakili konstruk laten yang sama. Construct reliability (CR) di atas 0.7 , variance extracted (VE) di atas 0.5 dan discriminant validity (DV) yang melebihi 0.7 merupakan standar pengukuran konsistensi internal dari indikator-indikator yang digunakan. Tabel 2 menunjukkan nilai $C R$ yang melebihi $0.7, \mathrm{VE}$ yang lebih besar dari 0.5 dan DV yang lebih besar dari 0.7 , serta semua nilai koefisien korelasi yang kurang dari akar kuadrat AVE untuk konstruk kebaruan produk, keunikan produk, daya tarik fashion dan kinerja pemasaran menunjukkan bahwa masingmasing instrument memiliki validitas yang baik dalam menjelaskan variabel-variabel penelitian yang digunakan.

Hasil pengujian pada full model persamaan struktural sudah sangat baik karena sudah memenuhi kriteria model fit yang diharapkan. Pertama, semua data yang digunakan sudah berdistribusi normal dan tidak ada data outlier. Kedua, nilai Chisquare 118.066 dan probabilitas ( $p$-value) 0.082 sehingga tidak signifikan pada $\alpha 0.05$. Ketiga, nilai GFI 0.955, AGFI 0.938, CFI 0.936 dan TLI 0.921 yang nilainya melebihi 0.90. Keempat, nilai CMIN/DF 1.205 yang lebih rendah dari 2, dan RMSEA 0.025 yang tidak melebihi 0.08 (Tabel 1). 
Tabel 2.

Reliabilitas Konstruk, Korelasi and AVE

\begin{tabular}{llcccc}
\hline \multicolumn{1}{c}{$\mathrm{N}=329$} & 1 & 2 & 3 & 4 \\
\hline 1. & Kebaruan Produk (KebP) & $0.720^{\mathrm{a}}$ & & & \\
2. & Keunikan Produk (KeuP) & 0.686 & 0.809 & & \\
3. & Daya Tarik Fashion (DTF) & 0.650 & 0.709 & 0.860 & \\
4. & Kinerja Pemasaran (KP) & -0.007 & 0.134 & 0.209 & 0.787 \\
\hline & Average Variance Extracted (AVE) & 0.737 & 0.828 & 0.870 & 0.819 \\
\hline
\end{tabular}

${ }^{a}$ Faktor reliabilitas ada pada diagonal.

Tabel 3.

Hasil pengujian regresi model persamaan struktural

\begin{tabular}{cccccccc}
\hline Hipotesis & Hub. Regresional & Std. $\beta$ & Unstd. $\beta$ & S.E & C.R & $p$-value & Keterangan \\
\hline H1 & KebP ---> DTF & 0.309 & 0.344 & 0.110 & 3.120 & 0.002 & Diterima \\
H2 & KeuP ---> DTF & 0.497 & 0.594 & 0.126 & 4.702 & 0.000 & Diterima \\
H3 & KebP ---> KP & -0.288 & -0.221 & 0.103 & - & 0.032 & Ditolak \\
H4 & KeuP ---> KP & 0.101 & 0.081 & 0.111 & 0.754 & 0.451 & Ditolak \\
H5 & DTF ---> KP & 0.324 & 0.224 & 0.083 & 2.705 & 0.007 & Diterima \\
\hline
\end{tabular}

Sumber : Data primer yang diolah, 2017

Tabel 3 dan Gambar 1 menjelaskan efek langsung pengaruh positip yang signifikan antara KebP terhadap DTF (Std. $\beta=0.309$, c.r $=3.120, p$-value $<0.01$ ), KeuP terhadap DTF (Std. $\beta=0.497$, c.r $=$ 4.702, $p$-value $<0.01$ ), dan DTF terhadap MP $(\operatorname{Std} \beta=0.324, c . r=2.6705, p<0.01)$. Sementara itu efek langsung tidak signifikan ditunjukkan oleh relasi KebP terhadap KP (Std $\beta=-0.288$, c. $r=-2.145, p$-value $<$ 0.05) dan efek KeuP terhadap KP (Std $\beta$ $=0.101, c . r=0.754, p$-value $>0.05)$. Hal ini menunjukkan hipotesis $\mathrm{H} 1, \mathrm{H} 2$, dan $\mathrm{H} 5$ diterima, sedangkan $\mathrm{H} 3$ dan $\mathrm{H} 4$ ditolak.

Berkenaan dengan $\mathrm{H} 6$ dan $\mathrm{H} 7$, Uji Sobel kedua anteseden mempengaruhi KP melalui DTF. Lebih khusus, DTF bertindak sebagai mediasi penuh dalam hubungan antara KebP dengan KP. Efek langsung KebP terhadap DTF dijelaskan oleh Unstd $\beta 0.344$, S.E 0.110 dan c.r 3.120 sehingga signifikan pada a 0.01. Efek langsung DTF terhadap KP dijelaskan oleh Unstd $\beta 0.224$, S.E 0.083 dan c.r 2.705 sehingga signifikan pada a 0.01. Efek tidak langsung KebP terhadap KP melalui DTF dijelaskan oleh koefisien Unstd $\beta 0.077$ (0.344 x 0.224). Pengujian dengan Sobel Test menghasilkan c.r 2.043, S.E 0.038 dan p-value 0.0410 sehingga signifikan pada $\alpha 0.05$. Total efek pengaruh KebP terhadap KP melalui DTF sebesar - $0.144(-0.221+0.077)$ yang lebih besar dari efek langsung (- 0.221) menunjukkan bahwa DTF memiliki peran yang sangat penting sebagai mediasi dalam hubungan KebP dengan KP dan menjadi alternatif penting dalam meningkatkan kinerja pemasaran usaha kecil. Oleh karena itu, studi ini menerima hipotesis $\mathrm{H} 6$.

Selain itu, DTF juga memediasi hubungan KeuP dengan KP. Efek langsung KeuP terhadap DTF dijelaskan oleh Unstd $\beta$ 0.594, S.E 0.126, c.r 4.702 dan $p$-value 0.007 sehingga signifikan pada $\alpha 0.01$. Efek langsung DTF terhadap KP dijelaskan oleh Unstd $\beta$ 0.224, S.E 0.083, c.r 2.705 dan $p$-value 0.007 sehingga signifikan pada $\alpha$ 0.01. Efek tidak langsung KeuP terhadap KP melalui DTF dijelaskan oleh koefisien Unstd $\beta 0.133$ (0.594 x 0.224). Pengujian dengan 


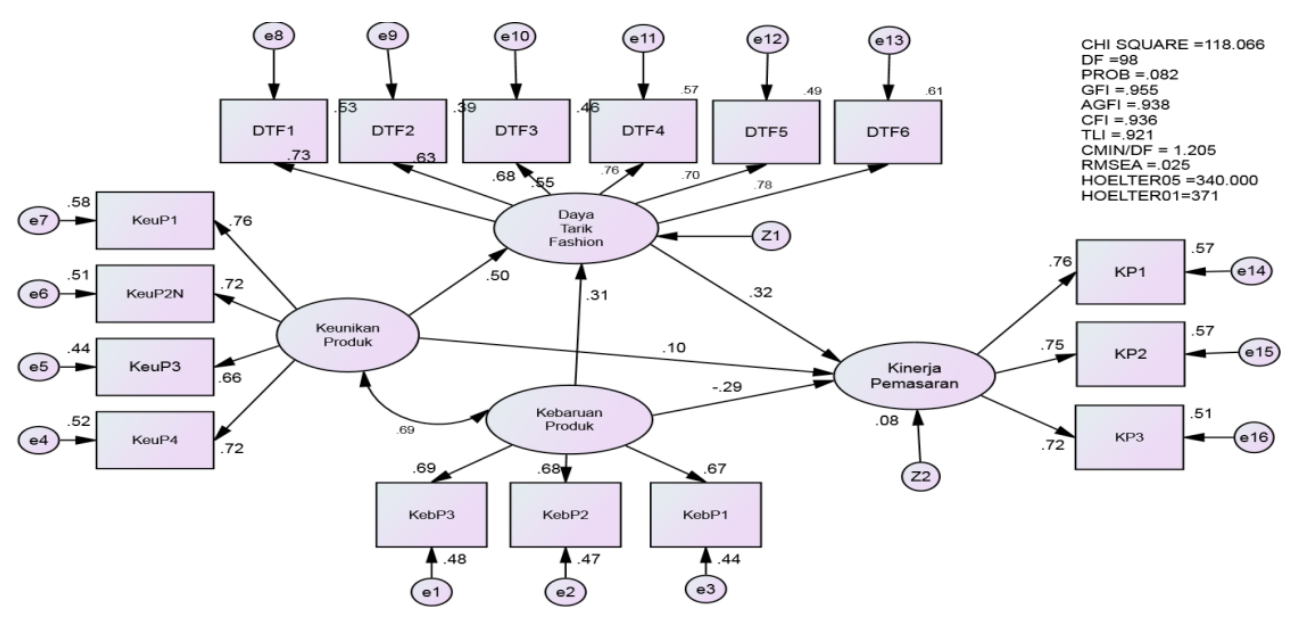

Gambar 1. Hasil pengujian model empirik

Tabel 4.

Estimasi parameter hasil pengujian Sobel Test

\begin{tabular}{|c|c|c|c|c|c|c|c|c|}
\hline & & Path & & & Unstd B & S.E. & c.r. & $\mathrm{P}$ \\
\hline KebP & ---> & DTF & ----> & $\mathrm{KP}$ & 0.077 & 0.038 & 2.043 & $0.041^{*}$ \\
\hline KeuP & ---> & DTF & ----> & $\mathrm{KP}$ & 0.127 & 0.054 & 2.322 & $0.020^{*}$ \\
\hline
\end{tabular}

Sobel Test menghasilkan c.r 2.322, S.E 0.054 dan $p$-value 0.020 sehingga signifikan pada $\alpha$ 0.05. Total efek pengaruh KeuP terhadap KP melalui DTF sebesar 0.214 $(0.081+0.133)$ yang lebih besar dari efek langsung (0.081) menunjukkan bahwa DTF memiliki peran yang sangat penting sebagai mediasi dalam hubungan KeuP dengan KP usaha kecil dan menjadi alternatif penting dalam meningkatkan KP usaha kecil. Oleh karena itu, studi ini menerima hipotesis $\mathrm{H} 7$.

\section{DISKUSI DAN SIMPULAN}

Tujuan utama dari penelitian ini adalah untuk menjelaskan hasil empiris yang bertentangan mengenai hubungan antara keinoasian produk dan kinerja pemasaran. Penelitian ini bertujuan untuk melakukannya dengan membuat konsep dan menguji secara empiris hubungan antara dua dimensi keinovasian produk (kebaruan produk dan keunikan produk) dengan kinerja pemasaran. Untuk mencapai tujuan ini, pertama hubungan antara kedua dimensi dengan daya tarik fashion dan kinerja pemasaran dihipotesiskan. Kedua, hipotesis pengaruh positip antara daya tarik produk dengan kinerja pemasaran ditetapkan. Hasilnya menunjukkan daya tarik fashion benar-benar menjadi faktor kunci peningkatan kinerja pemasaran. Ketiga, hipotesis peran mediasi daya tarik fashion dalam hubungan kebaruan produk dan keunikan produk dengan kinerja pemasaran ditetapkan. Hasilnya menunjukkan bahwa daya tarik fashion benar-benar sebagai mediator dalam hubungan antara kebaruan dan keunikan produk dengan kinerja pemasaran.

Dalam penelitian ini, keinovasian produk yang dioperasionalkan dengan kebaruan dan keunikan produk ditemukan sebagai faktor kunci peningkatan daya tarik produk. Itu berarti perusahaan yang berorientasi pada kebaruan produk (yang ditunjukan dengan kontinyuitas dalam merubah desain produk, rutin memperkenalkan produk dengan model baru ke pasar dan terus menyesuaikan kualitas bahan baku dengan kebutuhan pelanggan) akan memiliki kemampuan

EKOBIS Vol. 20, No.2, Juli 2019: 30 - 47 
yang lebih baik dalam menciptakan dan meningkatkan daya tarik produk fashion. Selain itu, perusahaan yang berorientasi pada keunikan produk (yang ditunjukan dengan kecenderungan perusahaan untuk menghasilkan produk dengan desain, model, corak dan kualitas bahan baku yang berbeda dari produk pesaing) akan memiliki kemampuan yang lebih baik dalam menciptakan dan meningkatkan daya tarik produk fashion.

Kebaruan produk dan keunikan produk ditemukan tidak berpengaruh dengan kinerja pemasaran. Secara umum, temuan ini tidak sejalan dengan beberapa hasil penelitian yang menunjukkan pengaruh positip keinovasian produk terhadap kinerja pemasaran (Matzler dkk., 2008; Akgu"n, dkk., 2009; Ar dan Baki, 2011; Alpay dkk., 2012; Dibrell, dkk., 2013). Secara parsial, temuan ini sejalan dengan Avlonitis dan Salavou (2007) yang menunjukkan bahwa kebaruan produk, baik kebaruan produk untuk perusahaan maupun kebaruan produk untuk basar, tidak berdampak pada kinerja produk baru. Namun temuan ini bertentangan dengan Talke, dkk. (2009) yang menemukan kebaruan desain adalah dimensi yang relevan dari keinovasian produk dan menjadi pendorong penting bagi kinerja pemasaran. Memang banyak studi empiris dalam literatur kinerja NPD mengambil perspektif perusahaan terhadap kebaruan. Semua hubungan yang mungkin antara kebaruan dan kesuksesan pasar telah ditemukan sangat bervariasi mulai dari hubungan berbentuk $U$, linier, dan berbentuk $U$ terbalik ketika berpindah dari inovasi produk rendah ke sedang kemudian ke produk yang sangat inovatif (Trijp dan Kleef, 2008). Produk-produk baru yang memberikan diferensiasi konsumen relatif terhadap pasokan pasar yang ada memiliki probabilitas yang lebih tinggi dari keberhasilan pasar (Trijp dan Kleef, 2008).

Pengaruh langsung yang tidak signifikan antara kebaruan dan keunikan produk terhadap kinerja pemasaran mungkin disebabkan karakteristik produk fashion muslim yang terikat dengan norma-norma religi. Kebarauan dan keunikan produk akan sulit mendapatkan respon yang baik dari pelanggan bila produk yang ditawarkan menyimpang dari norma syariah. Sebaliknya, kebaruan dan keunikan fashion muslim yang berbasis syariah akan menghasilkan daya tarik produk bagi pelanggan religius. Keadaan ini pada akhirnya akan memicu peningkatan kinerja pemasaran usaha mikro, kecil dan menengah busana musim. Dalam Islam, busana muslim adalah proteksi kemuliaan sekaligus martabat yang hakiki bagi seorang perempuan. Karena itu, fashion yang tidak Islami akan sanga sulit diterima di kalangan muslim yang taat. Selain itu, kesederhanaan berbusana adalah bagian dari iman. Akibatnya seorang Muslim akan berhati-hati menjaga penampilannya, berbusana santun, menjaga harkat dan martabat, serta menikmati apa yang Allah ciptakan sesuai tujuan menggunakan pakaian dan perhiasan (Boulanouar, 2006; Ahmad, dkk., 2014).

Daya tarik fashion ditemukan berpengaruh positip terhadap kinerja pemasaran. Nampaknya dalam industri fashion perusahaan yang memiliki kemampuan mengembangkan atribut produk dengan baik dehingga menghasilkan daya tarik produk yang lebih baik akan memacu peningkatan kinerja pemasaran. Umumnya, daya tarik produk memiliki pengaruh penting terhadap penggunaan produk (Quinn dan Tran, 2010) dan konsekuensinya kinerja pemasaran akan terus meningkat ketika tingkat penggunaan produk meningkat. Selain itu, pengaruh positip daya tarik fashion terhadap kinerja pemasaran sekaligus menunjukkan peran penting agama dalam pemasaran produk fashion muslim (Bakar, dkk., 2013; El-Bassiouny, 2014). Sebagai contoh, komunikasi pemasaran melalui simbol-simbol agama menjadi isyarat visual penting penanda daya tarik produk. Agama memberikan kesempatan bagi pemasar untuk mengembangkan kegiatan pemasaran 
untuk melayani pelanggan religius dengan menggunakan isyarat keagamaan seperti melalui daya tarik kemasan produk (Bakar dkk., 2013). Nampaknya perusahaan yang mampu mengelola atribut simbolik keagamaan sehingga menghasilkan daya tarik fashion berbasis norma-norma religi akan memiliki kemampuan yang lebih baik dalam meningkatkan kinerja pemasarannya. Daya tarik fashion yang dimaksud adalah model produk religi yang sesuai perkembangan mode, terkandung nilai kesederhanaan dan kesantunan, gaya mengikuti trend, estetik dalam desain, serta memiliki kenyamanan dan menjamin keamanan pemakainya (Boulanouar, 2006).

Hasil pengujian Sobel menunjukkan daya tarik fashion benar-benar sebagai mediator penting dalam hubungan kebaruan produk dan keunikan produk dengan kinerja pemasaran UMKM. Itu berarti, kebaruan dan keunikan produk yang ditawarkan UMKM ke pasar hanya akan berdampak positip pada kinerja pemasaran bila kebaruan dan keunikan produk tersebut mampu menghasilkan daya tarik fashion bagi pelanggan. Temuan ini membuktikan betapa penting peran daya tarik fashion bagi UMKM yang bergerak dalam industri fashion berbasis religi. Dalam lingkungan yang sangat dinamis dan karakteristik siklus hidup produk fashion yang pendek, permintaan tidak stabil, sulit untuk diprediksi dan tingkat pembelian impuls yang tinggi (Christopher $d k k ., 2004)$, mengharuskan UMKM secara kontinyu menghasilkan produk-produk baru yang unik yang menawarkan daya tarik bagi pelanggan.

Ditemukannya daya tarik fashion sebagai mediator yang meyakinkan dalam hubungan kebaruan dan keunikan produk dengan kinerja pemasaran, telah memberi referensi baru dalam menyelesaikan kontroversi hubungan keinovasian produk (kebaruan dan keunikan produk) dengan kinerja pemasaran. Hasil penelitian ini telah mengkonfirmasi peran sumber daya internal dalam memperkuat daya tarik fashion, seperti sumber daya insani dan entrepreneurial. Sebagai driver internal daya tarik fashion, kebaruan dan keunikan produk muncul ketika perusahaan memiliki dan mengembangkan budaya inovasi yang kuat. Pada industri fashion, inovasi merupakan proses yang berkesinambungan dan keberhasilan inovasi tersebut ditentukan oleh adopsi mayoritas konsumen di pasar (Cappetta, dkk., 2006). Budaya inovasi yang kuat memungkinkan seluruh komponen perusahaan bekerja keras menemukan ideide baru yang mendorong kemajuan usaha, melakukan eksperimen yang bermanfaat bagi kemajuan usaha, terus menerus memperbaiki penampilan produk, dan bekerja keras dalam memperbaharui model produk yang ditawarkan (Acar dan Acar, 2012; Alpay dkk., 2012; McGrath, 2013; Sheng, dkk., 2013).

\section{Implikasi manajerial}

Untuk menghasilkan daya tarik fashion perusahaan perlu terus menerus meningkatkan kebaruan dan keunikan produk. Ini dapat dilakukan dengan pendekatan berbasis religi. Mempertimbangkan nilai-nilai religius dalam membangun daya tarik fashion di pasar yang bersifat religius merupakan kebutuhan mendasar untuk memacu peningkatan kinerja pemasaran UMKM busana muslim. Temuan ini menyarankan tanggung jawab pemilik atau pengelola untuk secara serius dalam merancang dan menghasilkan produk-produk baru yang unik berbasis norma-norma religi sehingga menghasilkan daya tarik fashion dan kinerja pemasaran yang lebih baik. Budaya orientasi inovasi membantu dalam menciptakan daya tarik fashion tersebut melalui penciptaan ideide baru yang memudahkan mereka untuk menghasilkan produk-produk baru yang unik dan sesuai dengan norma-norma agama, disamping menjalin hubungan yang lebih harmonis dengan pelanggan, memberikan layanan yang lebih baik, melakukan promosi yang efektif dan efisien, serta 
memperbaharui strategi penjualan untuk tujuan menciptakan atau meningkatkan nilai bagi pelanggan.

\section{Keterbatasan dan Agenda Penelitian Mendatang}

Penelitian ini gagal membuktikan peran langsung keinovasian produk (kebaruan dan keunikan produk) dalam peningkatan kinerja, padahal beberapa temuan empirik masa lalu telah membuktikan adanya keterkaitan keinovasian produk terhadap kinerja pemasaran (Matzler dkk., 2008; Akgu"n dkk., 2009; Ar dan Baki, 2011; Rosli dan Sidek, 2013; Cheng, dkk., 2014). Temuan ini memunculkan kesenjangan penelitian baru yang perlu mendapat perhatian lebih dari peneliti mendatang. Selain itu, penelitian ini belum mencerminkan generalisasi yang luas karena populasi yang ditetapkan hanya mencakup pelaku UMKM busana muslim, sementara pelaku usaha besar serta pelaku bisnis produk berbasis religi non Islam belum dilakukan. Karena itu, penelitian lanjutan yang mereflikasi model daya tarik fashion ini dapat dilakukan dengan melibatkan seluruh perusahaan berbasis religi, baik yang berskala mikro, kecil, menengah, maupun besar. Lingkup penelitian juga bisa diperluas hingga area nasional atau bahkan internasional. Inisiatif penelitian di masa datang juga bisa melibatkan variabel kontingensi yang memoderasi keterkaitan antar variabel dalam model empirik penelitian ini, seperti ukuran perusahaan, tingkat religiusitas, selera pelanggan, patwa ulama, dan lain-lain.

\section{DAFTAR PUSTAKA}

Acar, A. Z. dan Acar, P. 2012. The effects of organizational culture and innovativeness on business performance in healthcare industry. Procedia - Social and Behavioral Sciences Vol. 58 (2012): pp. $683-692$.

Ahmad, N., dkk. 2014. IMPACT OF ISLAMIC FASHION MARKETING ON ISLAMIC MARKETING: "A CASE STUDY OF PAKISTANI WOMEN'S". Kuwait Chapter of Arabian Journal of Business and Management Review Vol. 3, No.5; Jan. 2014, Vol. 3(No. 5 (Jan. 2014)): pp. 66-72.

Akgu"n, A. E.; Keskin, H. dan Byrne, J. 2009. Organizational emotional capability, product and process innovation, and firm performance : An empirical analysis. Journal of Engineering and Technology Management, 26 (2009): pp. 103 - 130.

Alpay, G., dkk. 2012. How does innovativeness yield superior firm performance ? The role of marketing effectiveness. Innovation : Management, policy \& practice, Volume 14(Issue 1): pp. $107-128$.

Ar, I. M. dan Baki, B. 2011. Antecedents and performance impacts of product versus process innovation. Empirical evidence from SMEs located in Turkish science and technology parks. European Journal of Innovation Management, Vol. 14 (No. 2): pp. 172-206.

Atalaya, M.; Anafarta, N. dan Sarvanc, F. 2013. The relationship between innovation and firm performance: An empirical evidence from Turkish automotive supplier industry. Procedia - Social and Behavioral Sciences, Vol. 75 (2013): pp. 226- 235.

Avlonitis, G. J. dan Salavou, H. E. 2007. Entrepreneurial orientation of SMEs, product innovativeness, and performance. Journal of Business Research, Vol. 60 (2007): pp. 566575 .

Bakar, A.; Lee, R. dan Rungie, C. 2013. The effects of religious symbols in product packaging on Muslim consumer responses. Australasian Marketing Journal 21 (2013) 198-204, Vo. 21 (2013): pp. 198-204. 
Barnes, L.; Hayes, S. G. dan Jones, N. 2006. Fast fashion: a financial snapshot. Journal of Fashion Marketing and Management: An International Journal, 10(3): 282-300.

Baron, R. M. dan Kenny, D. A. 1986. The Moderator-Mediator Variable Distinction in Social Psychological Research: Conceptual, Strategic, and Statistical Considerations Journal of Personality and Social Psychology Vol. 51, No. 6, 1173-1182 (No. 6): pp. 1173-1182.

Boulanouar, A. W. 2006. The Notion of Modesty in Muslim Women's Clothing: An Islamic Point of View. New Zealand Journal of Asian Studies, Vol. 8(No. 2 (December, 2006)): pp. 134-156.

Cappetta, R.; Cillo, P. dan Ponti, A. 2006. Convergent designs in fine fashion : An evolutionary model for stylistic innovation. Research Policy, Vol. 35 (2006): pp. 1273 - 1290.

Carbon, C.-C. dan Leder, H. 2005. The Repeated Evaluation Technique (RET). A method to capture dynamic effects of innovativeness and attractiveness. Applied Cognitive Psychology, 19(5): 587-601.

Chan, S. L.; Ip, W. H. dan Cho, V. 2010. A model for predicting customer value from perspectives of product attractiveness and marketing strategy. Expert Systems with Applications, 37(2): 1207-1215.

Chang, H.-C.; Lai, H.-H. dan Chang, Y.-M. 2007. A measurement scale for evaluating the attractiveness of a passenger car form aimed at young consumers. International Journal of Industrial Ergonomics, 37(1): 21-30.

Chen, I.-S. 2010. THE EFFECTS OF PRODUCT ATTRACTIVENESS, BRAND INNOVATIVENESS, AND MONETARY PRICE ON PRODUCT EVALUATIONS: CASES OF THE TAIWAN AND UNITED STATES OF AMERICA MOBILE PHONE INDUSTRY. Dissertation : Presented to the Graduate Faculty of the Marshall Goldsmith School of Management Alliant International University.

Cheng, C. C. J.; Yang, C.-I. dan Sheu, C. 2014. The link between eco-innovation and business performance: a Taiwanese industry context. Journal of Cleaner Production, Vol. 64 pp. 81-90.

Christopher, M.; Lowson, R. dan Peck, H. 2004. Creating agile supply chains in the fashion industry. International Journal of Retail \& Distribution Management, 32(8): 367-376.

Clausen, T. H.; Korneliussen, T. dan Madsen, E. L. 2013. Modes of innovation, resources and their influence on product innovation : Empirical evidence from R\&D active firms in Norway. Technovation, Vol. 33 (2013): pp. 225-233.

Cooper, R. G. dan Kleinschmidt, E. J. 2007. WINNING BUSINESSES IN PRODUCT DEVELOPMENT: THE CRITICAL SUCCESS FACTORS. Technology Management, May June (2007).

Dibrell, C.; Craig, J. B. dan Neubaum, D. O. 2013. Linking the formal strategic planning process, planning flexibility, and innovativeness to firm performance. Journal of Business Research, xxx (2013): No. pp. 8.

El-Bassiouny, N. 2014. The one-billion-plus marginalization: Toward a scholarly understanding of Islamic consumers. Journal of Business Research, 67(2): 42-49.

Fandos, C. dan Flavia'n, C. 2006. Intrinsic and extrinsic quality attributes, loyalty and buying intention: an analysis for a PDO product. British Food Journal, Vol. 108(No. 8): pp. 646-662.

Ferdinand, A. T. dan Fitriani, L. K. 2015. Acculturative Iconic Product Attractiveness and Marketing Performance. Journal of Global Strategic Management, 2(9): 15-15.

Fuentes, J. B. dan Quiroga, E. 2009. The "Fashion-form" of Modern Society and its Relationship to Psychology. The Spanish Journal of Psychology, Vol. 12, No. 1, 383-390(No. 1): pp. 383-390.

Gao, Y. 2010. Measuring marketing performance: a review and a framework. The Marketing 
Review, Vol. 10 (2010)(No. 1).

Garcia, R. dan Calantone, R. 2002. A critical look at technological innovation typology and innovativeness terminology : a literature review. The Journal of Product Innovation Management, Vol. 19 (2002): pp. 110 - 132.

Giese, J. L., dkk. 2014. Advancing the aesthetic middle principle: Trade-offs in design attractiveness and strength. Journal of Business Research, 67(6): 1154-1161.

Hair, J. F., dkk. 2010. Multivariate Data Analysis (Seventh Edition). Pearson Prentice Hall. New Jersey, USA. , Paper, 816 pp (ISBN-13: 9780138132637).

Hayes, A. F. dan Preacher, K. J. 2014. Statistical mediation analysis with a multicategorical independent variable. Br J Math Stat Psychol, 67(3): 451-470.

Healy, B.; Ledwith, A. dan O'Dwyer, M. 2014. Perceptions of product advantage, NPD and organisational performance. Journal of Small Business and Enterprise Development, Vol. 21(No. 1): pp. 49-69.

Hendar, H.; Ferdinand, A. T. dan Nurhayati, T. 2017. Introducing the religio-centric positional advantage to Indonesian small businesses. Management \& Marketing, 12(1).

Hersleth, M., dkk. 2015. Effects of evoked meal contexts on consumers' responses to intrinsic and extrinsic product attributes in dry-cured ham. Food Quality and Preference, 40: 191-198.

Knotts, T. L.; Jones, S. C. dan Udell, G. G. 2012. Does On-Market Experience Make Products More Attractive to Mass Retailers ? Academy of Entrepreneurship Journal, Volume 18(Number 2): pp. 57-70.

Kotler, P. dan Keller, K. L. 2009. MARKETING MANAGEMENT, THIRTEENTH EDIRION. Pearson Education Limited. FT Prentice Hall.

Lamb, C. W.; Joseph F. Hair, J. dan McDaniel, C. 2010. Marketing. Tenth Edition. SouthWestern Cengage Learning 5191 Natorp Boulevard Mason, OH 45040 USA. Instructor's Edition ISBN-10: 0-324-59228-0.

Lancaster, K. J. 1966. A New Approach to Consumer Theory. The Journal of Political Economy, Vol. 74(No. 2 (Apr., 1996)): pp. 132-157.

Lee, L. T.-S. 2008. The effects of team reflexivity and innovativeness on new product development performance. Industrial Management \& Data Systems, Vol. 108 (2008)(No. 4): pp. $548-569$.

Lee, S.; Ha, S. dan Widdows, R. 2011. Consumer responses to high-technology products: Product attributes, cognition, and emotions. Journal of Business Research, 64(11): 11951200.

Lievens, F. dan Highhouse, S. 2003. The relation of instrumental and symbolic attributes to a company's attractiveness as an employer. Personnel Psychology; Spring 2003; 56, 1; ABI/ INFORM Complete pg. 75.

Lumpkin, G. T. dan Dess, G. G. 1996. CLARIFYING THEENTREPRENEURIALORIENTATION CONSTRUCT AND LINKING IT TO PERFORMANCE. Academy of Management Review, Vol. 21(No. 1): pp. $135-172$.

Mason, K. dan Bequette, J. 1998. Product experience and consumer product attribute inference accuracy. JOURNAL OF CONSUMER MARKETING, VOL. 15(N. 4 (1998)): pp. 343357.

Matzler, K., dkk. 2008. The Relationship between Transformational Leadership, Product Innovation and Performance in SMEs. Journal of Small Business and Entrepreneurship, Vol. 21(No. 2): pp. 139-152.

McGrath, R. G. 2013. The End Competitive Advantage : How Keep Your Strategy Moving as Fast as Your Business. Harvard Business Review Press Boston, Massachusetts.

McNally, R. C.; Cavusgil, E. dan Calantone, R. J. 2010. Product Innovativeness Dimensions

Mediasi Daya Tarik Fashion (Hendar) 
and Their Relationships with Product Advantage, Product Financial Performance, and Project Protocol. J PROD INNOV MANAG, Vol. 27: pp. 991-1006.

Merrilees, B.; Rundle-Thiele, S. dan Lye, A. 2011. Marketing capabilities: Antecedents and implications for B2B SME performance. Industrial Marketing Management, 40 (2011) 368-375.

Millson, M. R. 2013. Exploring the moderating influence of product innovativeness on the organizational integration new product market success relationship. European Journal of Innovation Management, Vol. 16(No. 3): pp. 317 - 334.

Moorman, C. 1995. Organizational Market Information Processes : Cultural Antecedents and New Product Outcomes. Journal of Marketing Research, Vol. 32(No. 3): pp. 318-335.

Morgan, N. A.; Clark, B. H. dan Gooner, R. 2002. Marketing productivity, marketing audits, and systems for marketing performance assessment Integrating multiple perspectives. Journal of Business Research, Vol. 55: pp. 363-375.

Oliver, C. 1997. SUSTAINABLE COMPETITIVEADVANTAGE: COMBINING INSTITUTIONAL AND RESOURCEBASED VIEWS. Strategic Management Journal, Vol. 18:9, 697-713 (1997).

Ortega, M. J. R. dan Garcia-Villaverde, P. M. 2011. Pioneer orientation and new product performance of the firm : Internal contingency factors. JOURNAL OF MANAGEMENT \& ORGANIZATION, Volume 17, Issue 4, July 2011.

Parasuraman, A.; Zaithaml, V. A. dan Berry, L. L. 1985. A Conceptual Model of Service Quality and Its Implications for Future Research. Journal of Marketing, Vol. 49 (Fall 1985): pp. 41-50.

Prasertsang, S. dan Ussahawanitchakit, P. 2011. CORPORATE SOCIAL RESPONSIBILITY STRATEGY, MARKETING PERFORMANCE AND MARKETING SUSTAINABILITY: AN EMPIRICAL INVESTIGATION OF ISO 14000 BUSINESSES IN THAILAND. INTERNATIONAL JOURNAL OF BUSINESS STRATEGY, Volume 11, Number 3, 2011, Volume 11(Number 3, 2011.): pp. 58 - 77.

Preacher, K. J. dan Hayes, A. F. 2008. Asymptotic and resampling strategies for assessing and comparing indirect effects in multiple mediator models. Behavior Research Methods, 40(3): 879-891.

Quinn, J. M. dan Tran, T. Q. 2010. Attractive Phones Don't Have To Work Better: Independent Effects of Attractiveness, Effectiveness, and Efficiency on Perceived Usability. Mobile Device Interaction: pp. 353-362.

Rosli, M. M. dan Sidek, S. 2013. The Impact of Innovation on the Performance of Small and Medium Manufacturing Enterprises: Evidence from Malaysia. Journal of Innovation Management in Small \& Medium Enterprise, Vol. 2013 (2013), Article ID 885666, 16 pages.

Salavou, H. dan Avlonitis, G. 2008. Product innovativeness and performance: a focus on SMEs. Management Decision, Vol. 46(No. 7): pp. 969-985.

Sandvik, I. L. dan Sandvik, K. r. 2003. The impact of market orientation on product innovativeness and business performance. Intern. J. of Research in Marketing, Vol. 20 (2003): pp. 355-376.

Sheng, S.; Zhou, K. Z. dan Lessassy, L. 2013. NPD speed vs. innovativeness: The contingent impact of institutional and market environments. Journal of Business Research, 66 (2013): 2355-2362.

Sobel, M. E. 1982. Asymptotic Confidence Intervals for Indirect Effects in Structural Equation Models. Sociological Methodology, Vol. 13: pp. 290-312.

Soliman, H. S. 2011. Customer Relationship Management and Its Relationship to the Marketing Performance. International Journal of Business and Social Science, Vol. 2(No. 
10, June 2011).

Srivastava, R. K.; Shervani, T. A. dan Fahey, L. 1999. Marketing, Business Processes, and Shareholder Value: An Organizationally Embedded View of Marketing Activities and the Discipline of Marketing. Journal of Marketing, Vol. 63 (Special Issue 1999), 168-179.

Talke, K., dkk. 2009. What about Design Newness? Investigating the Relevance of a Neglected Dimension of Product Innovativeness. J PROD INNOV MANAG, Vol. 26: pp. 601615.

Trijp, H. C. M. v. dan Kleef, E. v. 2008. Newness, value and new product performance. Trends in Food Science \& Technology, Vol. 19(No. 11): pp. 562-573.

Wood, L. 2007. Functional and symbolic attributes of product selection. British Food Journal, Vol. 109(No. 2): pp. 108-118.

Yalcinkaya, G.; Calantone, R. J. dan Griffith, D. A. 2007. An Examination of Exploration and Exploitation Capabilities: Implications for Product Innovation and Market Performance. Journal of International Marketing, Vol. 15, No. 4, 2007: pp. 63-93.

Zhang, Z., dkk. 2002. Casual wear product attributes. Journal of Fashion Marketing and Management: An International Journal, 6(1): 53-62.

Zineldin, M. 2006. The royalty of loyalty: CRM, quality and retention. Journal of Consumer Marketing, Vol. 23(No. 7 (2006)): pp. 430-437. 